Проказин Виктор Валентинович

кандидат философских наук,

доцент кафедры философии и социологии

Амурского государственного университета

\section{КРИТИКА ИДЕИ ПРОГРЕССА В.М. ХВОСТОВЫМ}

\begin{abstract}
Аннотация:
Статья посвящена анализу основных направлений критики идеи прогресса В.М. Хвостовым, русским социологом XIX - начала XX в. Разбираются логические, гносеологические, этические и фактологические аргументы доказательства несостоятельности и практической вредности идеи и социологических теорий прогресса.
\end{abstract}

\section{Ключевые слова:}

история социологии, русская социология XIX начала $X X$ в., проблематика прогресса, теории прогресса, логическая, фактологическая, гносеологическая, этическая критика идеи и теорий прогpecca.

\section{Prokazin Viktor Valentinovich}

PhD, Assistant Professor Philosophy and Sociology Department, Amur State University

\section{CRITICISM OF THE IDEA OF PROGRESS BY V.M. KHVOSTOV}

Summary:

The article analyzes the main directions of criticism of the idea of progress by V.M. Khvostov, the Russian sociologist of $X I X$ - early $X X$ centuries. It reviews the logical, epistemological, ethical and factual arguments for evidence of insolvency and practical harmfulness of the idea and sociological theories of progress.

Keywords:

history of sociology, Russian sociology of XIX - early $X X$ centuries, problems of progress, theories of progress, logical, factual, epistemological, ethical criticism of the idea and theories of progress.

Со второй половины XIX - начала XX в. в социологической науке разворачивается широкая и разносторонняя критика одной из ее собственных ключевых идей - идеи прогресса. Наука и практика выявляют многочисленные фракты, противоречащие этой идее, фрормируются многообразные формы и направления доказательства ее несостоятельности [1].

Вениамин Михайлович Хвостов, русский социолог неокантианского направления, юрист, не считает возможным применять понятие прогресса не только в положительной науке, но даже в философских построениях исторического процесса или социальной эволюции. Опасно также, по его мнению, ее использование в практической деятельности.

Критически оценивая эвристические возможности понятия прогресса, социолог исходит из задач познания вообще. Человеческое познание должно давать по возможности наиболее полную картину реальности.

Объектом социологии и истории является общество, но изучают они его по-разному: социология - это наука обобщающая, наука о законах, а история - дисциплина индивидуализирующая, наука о единичном. Социология и история изучают общество в динамике. По мнению социолога, эволюция есть единый, последовательный процесс изменений, который мы можем изучить как связное целое [2]. Изучать эволюцию можно с двух основных позиций - причинной и телеологической. Использование и того, и другого подходов в науке вполне правомерно. Безусловно, научным является каузальное, то есть причинное, объяснение исторического процесса. Однако допустим и телеологический подход: события представляются нам как бы стремящимися к своей цели, которой они могут и не достигнуть; эволюция может оказаться законченной и успешной или же незаконченной и неуспешной. Однако применение телеологизма возможно с одним важным условием: существо телеологической группировки исторических событий состоит не в том, чтобы связать их с той целью, к которой, по мнению самого исследователя, движется история, а в том, чтобы изучать историческую жизнь с точки зрения тех целей, которые люди преследуют в своей деятельности. Нарушение этого условия ведет к появлению в научном исследовании исторической эволюции «гипотетических и метафизических элементов» [3, с. 50].

Таким элементом является внесение в исследование идеи прогресса. Хвостов подвергает понятие прогресса всесторонней критике - логической, философской, этической и фактической.

Он пишет, что очень часто исследователи используют понятие прогресса, не давая себе труда точно определить и подвергнуть его анализу с точки зрения применимости в науке. Это понятие не может быть считаемо строго научным, что вытекает из самого его определения: «Прогресс есть развитие, направленное к цели, которой мы придаем положительную ценность» [4]. Именно присутствие субъективно-оценочного момента делает невозможным использование идеи прогресса в строго научных изысканиях. 
Кроме того, идея прогресса не выдерживает критики и в других отношениях. Хвостов пишет, что во всех рассуждениях о прогрессе приходится исходить их двух предпосылок: 1) чтобы сказать, что данная цель имеет положительную ценность, следует располагать определенным мерилом ценности, 2) чтобы утверждать наличность прогресса в истории, надо доказать, что человечество действительно идет в сторону достижения этой цели [5]. Обе эти предпосылки оказываются недоказуемыми с точки зрения науки. Так, если говорить об определении мерила ценности цели прогресса, то в истории идеи прогресса выделяются два основных подхода - так называемый моральный и эвдемонистический. С точки зрения первого ценность человеческого существования заключается в выполнении морального долга. Существо морального долга раз и навсегда установлено, и мы должны ему подчиняться, не заботясь о счастье. Другая - эвдемонистическая - позиция состоит в признании самым ценным в жизни человеческого счастья. Никакого долга без отношения к человеческому счастью нет. Таким образом, эти точки зрения относительно критерия ценности прямо противоположны. Более того, даже если мы согласимся считать мерилом ценности масштаб счастья или благосостояния и признавать прогрессом то, что ведет нас к этой цели, то возникает ряд вопросов, которые невозможно разрешить средствами опытной науки. Все эти вопросы чисто метафизические. Вторая предпосылка также научными методами не доказуема. В. Хвостов пишет, что «мы можем доказать, что с течением времени увеличивается сумма знаний, делается больше и глубже этическое воззрение, но не знаем, становится ли человечество моральнее в самом своем поведении и делается ли оно счастливее» [6, с. 7]. Наконец, нельзя поручиться за то, что процесс культурного развития человечества всегда будет идти непрерывно. А без этого условия невозможен всемирно-исторический прогресс. Таким образом, что касается чисто научных теоретических изысканий, то вводить в них понятие прогресса в качестве руководящей идеи не следует ни в каком случае, так как оно содержит в себе выходящие за пределы доказуемого знания метафизические элементы.

Если все эти вопросы не могут быть разрешены наукой, то возможны ли теории прогресса вне области научного знания? В. Хвостов всерьез интересовался вопросами этики и философии. Наряду с опытным миром существует, по его мнению, особая реальность - «мистическая». Мистическая реальность - это сфрера, где ставятся и решаются вопросы о том, «есть ли в жизни положительный смысл или нет, что такое добро и зло и каково их соотношение в мире» и т. п. Это - область индивидуальных и социальных идеалов, область веры. Наше миропонимание, как считает В. Хвостов, должно заключать в себе и этот телеологический элемент. Поэтому философские, метафизические построения реальности являются вполне правомерными. Рассмотрение подобных вопросов относится к области философии и этики.

В. Хвостов пишет, что у мыслителей, работавших в области философии истории, проблема прогресса совпадала с проблемой смысла всемирной истории, выступала как попытка «выяснить ту рациональную или иррациональную схему, которая лежит в основе всего исторического процесса, уже пережитого человечеством, и даже заглянуть на этом основании в будущее» [7]. Узнать смысл истории мы не можем и вряд ли когда-нибудь будем в состоянии это сделать. Первая причина имеет гносеологический характер, связана с уровнем и, главное, возможностями нашего познания. В. Хвостов пишет, что смысл исторического процесса нам совершенно неясен; будущее вполне неизвестно, прошедшее же не вполне известно. В истории реализуется какаято одна, основная тенденция. Нельзя утверждать, что мир движется только к добру, благу или только регрессирует и в нем восторжествует в конечном счете зло. Безотчетный оптимизм теорий прогресса не имеет оснований.

Теории прогресса, как отмечает В. Хвостов, пытаются научно предсказать будущее, определить перспективы социальной эволюции. Будущее методами науки принципиально не предсказуемо. В обществе постоянно идет процесс культурного творчества. Человек есть существо, обладающее свободой волей. В духовном творчестве следствие не содержится целиком в своих причинах; возникают постоянно новые продукты. Вот почему в этой области, то есть в обществе, невозможны точные предсказания.

Несостоятельны идея прогресса и его теории и с этической или практической точки зрения. Ссылаясь на Канта, В. Хвостов пишет, что если мы будем руководствоваться только верой в прогресс, то настоящий момент теряет самостоятельное значение. Он является лишь ступенью, которой воспользуется будущее. Однако истинно этическое мировоззрение должно пытаться отдать должное и настоящему моменту, признать самостоятельную ценность за нашими действиями во имя добра во всякий данный момент, независимо от их результатов в более или менее отдаленном будущем. Во-вторых, если бы мы наперед знали, чем окончится мировой процесс (а теория прогресса и предполагает констатацию такой конечной цели), то утратила бы для нас всякий смысл и интерес творческая деятельность. Идея прогресса вредна в практическом отношении. 
Не выдерживает, по мнению В. Хвостова, идея прогресса и фактической критики. Он пишет, что в истории нет постоянного и непрерывного движения человечества в каком-нибудь одном направлении. В ней бывают и периоды оживленной и кипучей деятельности, и периоды застоя и даже регресса. Нельзя утверждать и того, что развитие человечества шло непрерывно, так как бывали периоды, надолго нарушавшие преемственную связь культурного развития. Наконец, далеко не все еще человечество приняло участие в культурной работе. В. Хвостов отмечает, что даже если в какой-то области до сих пор замечался несомненный прогресс, то только в области чистой и прикладной науки. Да, несомненно, знания человечества постоянно расширяются и углубляются. Однако развитие знания и последствия такого развития могут иметь и имеют и другую сторону. Поэтому «создаваемое им господство человека над остальным миром может быть обращено как на служение добру, так и на цели зла» [8, с. 6]. Следовательно, прогресс знания может служить и регрессу. Достижения в одной области могут сопровождаться возникновением регрессивных проявлений. Таким образом, фактическая действительность не позволяет однозначно утверждать о наличии абсолютного прогресса в истории.

\section{Ссылки:}

1. Alexander J.C. Between progress and apocalypse: social theory and dream of reason in the twentieth century // Rethinking progress / eds: J. Alexander, P. Sztompka. L., 1990. P. 15-38.

2. Ibid.

3. Х Хостов В.М. Теория исторического процесса. Очерки по философии и методологии истории. М., 1914.

4. Alexander J.C. Op. cit.

5. Ibid.

6. Х Хостов В.М. Социальная связь // Вопросы философии и психологии. 1918. Кн. 141-142.

7. Alexander J.C. Op. cit.

8. Хвостов В.М. Нравственная личность и общество. Очерки по этике и социологии. М., 1911.

\section{References}

Alexander, JC \& Sztompka, P (eds.) 1990, 'Between progress and apocalypse: social theory and dream of reason in the twentieth century', Rethinking progress, London, pp. 15-38, https://doi.org/10.4324/9780203161906.

Khvostov, VM 1911, Moral personality and society. Essays on ethics and sociology, Moscow, (in Russian).

Khvostov, VM 1914, Theory of the historical process. Essays on philosophy and methodology of history, Moscow, (in Russian).

Khvostov, VM 1918, 'Social relation', Voprosy filosofii i psikhologii, Books 141-142, (in Russian). 